\title{
MEMORY STRATEGIES FOR THE PILOT
}

\author{
Gary J. Northam \\ Parks College of Engineering and Aviation \\ Saint Louis University
}

\begin{abstract}
Theorists have studied the problem of forgetting for a number of years; however, very little application has been made to the general aviation pilot. This paper considers some concepts for understanding the processes involved when important tasks are forgotten and/or certain "actionsnot-as-planned" are executed. While there are numerous ways suggested by memory specialists, a few may be particularly applicable to flight. Forgetting can be explained as an activation issue as defined in the concepts of action theory. A structural model of three stages is used to explain some psychological processes of the memory system. Finally, some suggestions for the practical enhancements of memory are offered along with recommendations for further memory research.
\end{abstract}

\section{INTRODUCTION}

In the United States there is, on the average, one gear up landing each day (Trollip and Jensen, 1990). According to AOPA's 1991 General Aviation Accident Analysis Book, this very common accident may not always be fatal, but it is costly. This type of accident can be attributed to a class of mistakes called "slips of action." The pilot neglects to use the landing checklist and subsequently experiences an incident or accident. Degani and Weiner (1990), in one survey of accident/ incident occurrences, found three significant accidents in a fifteen month period that could have been attributed to a misuse of the checklist (p.2). A recent ASRS Database Report on Checklist Incidents (1999) indicates that action errors are common. This report is a sampling of incidents from all different aviation areas and includes many negative results from the neglect or misuse of the normal checklist. Of all reports identified, $86 \%$ noted problems that resulted from action errors.

Another common mistake made by pilots that can result in embarrassment and considerable expense is the failure to close one's flight plan upon arrival at the destination. This is also the result of forgetfulness or action slips on the part of the pilot. Why do pilots fail to use the checklist properly? Why do pilots forget to close a flight plan upon arrival at the destination? Memory research may provide some insight into the cause of these lapses and suggest some recommendations for solving the problem.

\section{ACTION SLIPS AND MEMORY}

There are several ideas that attempt to explain what happens when one neglects 
to do a particular act or accomplishes an act different from the intended. Action slips may be classified as absent-mindedness and defined as actions "not as planned" (Reason and Mycielska, 1982). Hawkins (1987) summarizes these ideas in three areas. First, a person may forget simply because of the passage of time. If the information is not used regularly, it may decay and not be available for recall. A second idea about forgetting explains that the process of losing information relates to interference from other more memorable information. This conflicting information likely was presented to the pilot at a different time than the replaced data, but due to various factors exhibits a stronger influence. A third possibility described by Hawkins is that some forgetting is motivated. The information may have presented painful or anxious feelings and was then blocked from the conscious memory.

\section{Action Theory}

Forgetting may be classified as a type of breakdown as described by action theory. Norman (1981) considers human mistakes and defines certain of them as action errors. Pilots may perform a particular action regularly, but inadvertently neglect that same action at another time and commit an action slip. According to Norman, there are three stages of action slips:

1. the formation of intentions;

2. activation; and

3. triggering.

Errors may occur in each of these three stages and may be related to the problems of remembering. Action slips may occur when activation occurs unintentionally as when a pilot inadvertently selects a switch and trips it when it should not have been turned on. Action slips may also occur when activation to perform a particular task is lost. Neglecting to lower the landing gear when approaching to land may be an error caused by cues not being activated at the appropriate time.

\section{Faulty Activation}

A slip resulting from faulty activation of a schema is also called forgetting. A schema represents an element that triggers a memory. There is something that triggers the thought for a pilot to look at a checklist. If the pilot does not remember the checklist, he/she will not check it to make sure everything is completed for the accomplishment of an activity. Loss of activation describes the situation in which appropriate actions fail to be accomplished. Norman (1981) suggests that this creates a memory failure. Memory failure occurs when events intercede between preparing an intention for action and the accomplishment of the actual act. This explanation relates to the interference theory of forgetting. For example, when an airplane approaches a destination airport, the pilot is preparing to land. As the preparation for landing begins the pilot intends to lower the landing gear. Unexpected things may happen. ATC may give additional vectors or other instructions, and suddenly the workload increases. If the checklist is not used properly no verification will be made that the important items have been accomplished. The landing may occur with the gear retracted. On this occasion the checklist has been "forgotten" because the cue that leads the pilot to accomplish the checklist was not activated.

\section{Structural Model}

\section{Three Stages.}

Telfer and Biggs (1987) define memory systems with three stages, using a modification of the structural model defined 
by Atkinson and Shiffrin (1968). The first stage of this model is the sensory register. It is during this stage that a precoding of stimuli occurs. Based on the decision of the receiver, the physical properties of the stimuli, and the physiological state of the receiver, all information received is either accepted, precoded and sent to the working memory, or filtered out and ignored. Also important in the precoding process are one's background, beliefs, and other preconditioning. All this activity occurs within one second. After a second has passed, the stimulus has either been sent on with precoding or filtered out and ignored.

In stage two the stimuli that are precoded are transferred to the working memory. This process lasts about one minute. To illustrate this process of working memory, try this simple activity. Cover your eyes while someone writes a set of random digits on a chalkboard (e.g., 5,8,3,4,1,7,2,6). At a cue, look at the numbers for approximately 15 seconds and then have them erased. According to Miller (1956), a typical adult will be able to retain about seven digits, plus or minus two. There are ways to rearrange the digits to have more remembering success. If a similar number of digits are arranged sequentially in a pattern they can be remembered more easily. If the sequence of digits were $1,3,5,7,2,4,6,8$ they could be remembered easily. This is because you are actually remembering only 2 units $(1,3,5,7)$ and $(2,4,6,8)$ as if it had been $1,2,1,2$. This widely accepted principle is called "chunking" (Nairne, 1996). When stimuli can be associated together and connected with past experiences, it can be held in working memory more effectively. This process encompasses about one minute of time.

The third and final stage in the memory process, as defined by Telfer and Biggs, is "storage." A properly processed stimulus is transferred to long-term memory where it remains properly coded for a lifetime. One only has to activate the proper cue to return it to consciousness.

\section{Activation Errors}

Activation errors typically occur when the information is being transferred to the working memory. When the pilot is flying the enroute section of a trip, he/she is performing various tasks and planning the approach at the destination airport. The working memory is being used to get everything ready for the approach and landing. As was noted previously, the working memory maintains awareness for approximately one minute. As each cue is activated, the necessary tasks are accomplished. The radios are appropriately tuned and the pilot begins receiving vectors to the final approach course. A common problem that may occur at this point in the flight is distraction. Distraction can lead to forgetting to accomplish an important task, such as lowering the landing gear. He/she may activate the cue to review the prelanding checklist. As the checklist review is initiated, the controller gives an additional unexpected vector. That new stimulus interferes with the current activation by energizing a new set of cues. The pilot responds to this new set of cues, but loses the first activation and forgets to complete the checklist. Edwards (1990) says that most of these gear up accidents "seem to involve some piece of distraction...an unusual stress situation or an unexpected event" and this diverts his attention from the checklist (p.79). Morrison, Etem, \& Hicks (1993) studied one hundred fifty reports of landing phase incidents as reported in the ASRS data base. They found that $45 \%$ of the human and environmental factors underlying incidents involved distraction. This was almost twice the next closest factor.

The following quote from the October, 1991, Callback illustrates this 
problem.

"I was conducting a biennial flight review in a light aircraft. The pilot was asked to... make a short field landing... The pilot did not do a prelanding cockpit check which I...noted and intended to remind him of, later... The subsequent approach was hurried, low, with flaps coming down late and (the aircraft) off-centerline approaching the runway...I was distracted by watching the poor approach and failed to catch the fact that the gear was not down before the actual contact with the ground..."

Morrison, Etem, and Hicks (1993) conclude, "Many gear-up incidents and accidents could be prevented through a use of a written pre-landing checklist or reliable application of memory aides such as 'GUMP'." Pilots have, for a long time, used these types of mnemonics to create the required cue activation.

Another possible explanation for this error is that the pilot has simply forgotten to use the checklist. This occurs because of a different kind of action slip. In this situation the cue is not activated at all. A checklist is good only if remembered and there must be something to activate the "pre-landing checklist" cue. Researchers (Edwards, 1990; Hawkins, 1987; Trollip and Jensen, 1991) have suggested that the use of these aids is beneficial when dealing with the problem of "simply forgetting". Mnemonics, however, require activation so that they will not be forgotten.

\section{Enhancing Memory}

These activation problems typically are centralized in the working memory. For this reason, one should begin seeking solutions to "actions-not-as-planned" in the working memory. A number of researchers
(Biggs and Telfer, 1987; Biggs and Telfer, 1988; Edwards, 1990; Trollip and Jensen, 1991; Wickens and Flach, 1988) have suggested that rehearsal, the repeating of information over and over aloud, is a useful technique. This places the information firmly into long term storage. When dealing with the problem of numerous consecutive events near the approach phase of a flight, the pilot may recite a pre-rehearsed sequence of activities. For example, "Approach charts reviewed-check; navigation frequencies tuned and identified-check; communication frequencies set - check; pre-landing checklist performed - check," may be recited aloud. Rehearsal may help the pilot get through this very busy time without forgetting the details.

Wickens and Flach (1988) suggest that rehearsal is an excellent way to deal with the problem of "associative interference," their description for this theory of forgetting. They also propose that three steps may be required to assure that the appropriate cues are activated at the proper time.

1. Distribute the information over time. Similar stimuli may be confused if less than 10 seconds are allowed between the processing.

2. Reduce similarity and redundancy among the items.

3. Minimize the coding interference.

Coding interference occurs when the activation codes for one set of stimuli conflict with those of another. A pilot may attempt to remember the checklist, but an interfering cue takes its place and the use of the checklist is forgotten. Wickens and Flach (1988) define the coding process as either spatial or verbal. Spatial activation will more quickly interfere with other spatial cues and in the same way verbal activation will most likely interfere with other verbal cues. It would be to the pilot's advantage to note the type of 
information that is likely to interfere with remembering the pre-landing checklist and use the other to activate the appropriate cues. Distractions in the cockpit occur during the approach and landing phase of flight, so if the pilot can precode the activation cues for remembering the pre-landing checklist in spatial coding, there will be less interference. Edwards (1990) calls this loci and imaging. $\mathrm{He}$ suggests that something visual be connected with the task to be remembered. For example, the pre-landing checklist may be normally used as the pilot is descending from the enroute phase of flight to the approach phase. A visual picture would be created of a checklist floating down from the top of a room (the enroute) to a doorway (the beginning of the approach). The mental image is then rehearsed until it is incorporated into storage. The descent phase will then activate the imaging and the checklist will come into mind.

This process will become more effective if learning is related to knowledge already acquired. Biggs and Telfer (1987) describe this as the coding of learning to a particular knowledge base, and suggest that this makes the learning more meaningful. They describe it as "more economical, more stable and usually more enjoyable than rote learning" (p. 51). Hawkins (1987) carries it a step further by including in his list of memory enhancements "over-learning." The effective use of the checklist will more likely occur if the student is trained thoroughly. Overlearning occurs when the student knows the material so well that it becomes automatic. This requires an instructor to provide the required material then review it as many times as necessary for it to become automatic. In the case of flight instruction, as in any other skill training, a part of the process is practice. So, providing the information; emphasizing the importance of it; regular review, and regular practice can create the automatic response. If this is applied to learning the importance and necessity of using the checklist, the proper use will be entrenched. Even though distractions may occur at the most inopportune time, the use of the checklist will be automatic and will not be forgotten.

\section{CONCLUSION AND RECOMMENDATIONS}

A gear up landing is only one of many errors that may occur as a result of forgetting important piloting tasks. Many aviation errors can have serious consequences, so it is important to provide ways to assist the pilot during these situations. Concentration on remembering the important tasks during a flight can be enhanced with certain strategies.

This paper has suggested that forgetting or performing "actions-not-as-planned" may result from a task as simple as neglecting the proper use of the checklist. A quality checklist will always include those necessary items, so the pilot must assure its proper use.

Two items that have definite implications for the training environment are over-learning and rehearsal, both of which have been substantiated through scientific inquiry. These are items that can be easily emphasized in the training environment, and further exploration regarding ways to emphasize and teach them would be in order for future inquiry.

Boer (1997) suggests an additional emphasis that may support the pilot's education. He recommends that pilots be trained to understand when they are at risk of forgetting a particular task. It is understood and emphasized by the FAA that during certain periods of the flight, i.e., the approach and landing phase, skill and concentration demands are greater for the pilot. If the flight requirements are greater the chance of a distraction is increased. The pilot could then direct more attention toward 
remembering to do the essential tasks. Proper checklist use would be one result of this emphasis. Flight training device scenarios could be useful when teaching this pilot awareness; however, more investigation needs to be conducted on this training issue.
Finally, more research needs to be conducted on the concept of mental imagery. This approach to memory enhancement has potential for providing more effective strategies for remembering time-critical piloting tasks. 


\section{REFERENCES}

Biggs, J. B. \& Telfer, R. (1987). The Process of Learning. Sydney, Australia: Prentice-Hall.

Biggs, J. B. \& Telfer, R. (1988). The Psychology of Flight Training. Ames, Iowa: Iowa State University Press.

Boer, L. C. (1997). Remembering to do a task: An element of cockpit management. In H. Soekkha (Ed.), Aviation Safety: Proceedings of the International Aviation Safety Conference (pp. 455-464). Utrecht, Netherlands: VSP

Degani, A. \& Wiener, E. L. (1990). Human Factors of Flight-Deck Checklists: The Normal Checklist. Moffett Field, CA.: Ames Research Center, National Aeronautics and Space Administration.

Edwards, D. C. (1990). Pilot: Mental and Physical Performance. Ames, Iowa: Iowa State University Press.

Hawkins, F. H. (1987). Human Factors in Flight. Brookfield, Vermont: Gower Publishing Company.

Kelly, W. P. (1989). Checklist use and abuse. 1989 Pilot's Safety Handbook.

Miller, G. A. (1956). The magical number seven plus or minus two: Some limits on our capacity for processing information. Psychology Review, 63, 81-97.

Morgan, L. (1990). Lights, horns, bells, and whistles. Flying, March, 1989, 108, 110.

Morrison, R., Etem, K, \& Hicks, B. (1993) General aviation landing incidents and accidents: A review of ASRS and AOPA research findings. In The Ohio State University Seventh International Symposium on Aviation Psychology. Aviation Safety Reporting System publication.

Nairne, J. S. (1996). Short term/working memory. In E. L. Bjork\& R. A. Bjork. (Eds.)Memory (pp 101-123). San Diego: Academic Pressd3

National Aeronautics and Space Administration (1991). Much to be said on both sides. Callback, No. 149.

National Aeronautics and Space Administration (1990). Checklist reminders. Callback, No. 138.

National Aeronautics and Space Administration (1990). Human Factors and the Normal Checklist: Part 1. Callback, No. 136.

National Aeronautics and Space Administration (1990). Human Factors and the Normal Checklist: Part 2. Callback, No. 137.

Nelson, J. L. (1991). Checked and set? Don't let routines become routine. Flight Training, 3, 42-43.

Norman, D. A. (1983). Design rules based on analyses of human error. Communications of the ACM, 26, 254-258.

Norman, D. A. (1981). Categorization of action slips. Psychological Review, 88, $1-15$. 
Trollip, S. R. \& Jensen, R. S. (1991). Human Factors for General Aviation. Englewood, CO.: Jeppesen Sanderson, Inc.

Wickens, Christopher D. and Flach, John M. (1988). Information Processing. In E.L. Weiner and D.C. Nagel (eds.) Human Factors in Aviation. (pp. 111 - 155). New York: Academic Press, Inc. 